\title{
Los derechos humanos en la Conferencia de Seguridad y Cooperación en Europa
}

\author{
Por José Antonio PASTOR RIDRUEJO \\ Catedrático de Derecho Internacional \\ en la Universidad Complutense (Madrid)
}

\begin{abstract}
El tema de los derechos humanos en el ámbito de la Conferencia sobre Seguridad y Cooperación en Furopa ha alcanzado una importancia capital en las relaciones Este-Oeste. $I$ con resultados no desdeñables en absoluto desde una perspectiva realista.
\end{abstract}

\section{En el Acta Final de Helsinki}

I.--La paz y la distensión son los objetivos fundamentales de la Conferencia sobre Seguridad y Cooperación en Europa. En el Acta Final de Helsinki, efectivamente, los Estados participantes reafirman su intención de "lograr condiciones en las que sus pueblos puedan vivir en una paz auténtica y duradera" y se declaran convencidos ide la necesidad de realizar esfuerzos para conseguir que la distensión sea un proceso continuo y cada vez más viable y general, de dimensión universals.

Pero la paz y la distensión tienen un carácter global y profundo que rebasa los aspectos puramente militares, de seguridad y desarme, para incidir de lleno en el campo del respeto a los derechos humanos y la cooperación humanitaria. $Y$ ello no solamente porque la guerra constituye la más grave y flagrante violación de los derechos del hombre, sino también porque, como dijera el eminente internacionalista belga Charles de Visscher, existe un vínculo estrecho e indiscutible entre el respeto a los derechos humanos y libertades fundamentales en el interior del Estado y el mantenimiento de la paz entre los Estados. 


\section{A. PASTOR RIDRUEJO}

Tales ideas están presentes de modo claro en el Acta Final de Helsinkki. Así, cuando el principio VII del Decálogo habla de los derechos humanos dice que su "respeto es un factor esencial de la paz". Y de otro lado, uno de los aspectos más destacables del Acta es el equilibrio entre los principios que reafirman la soberanía del Estado y el status quo (I, III, IV y VI que se refieren respectivamente a la igualdad soberana, inviolabilidad de las fronteras, integridad territorial y no intervención en los asuntos internos) y el principio VII que trata del respeto a los derechos del hombre. Equilibrio que se repite luego entre el primer cesto del Acta-cuestiones de seguridad-y el tercero-cooperación en el campo humanitario y en otros campos--, cuya relación con los derechos humanos es manifiesta.

En una óptica política hay que decir que el tema de los derechos humanos fue introducido en las negociaciones y llevado al Acta Final por las delegaciones occidentales y precisamente como contrapartida del principio de inviolabilidad de las fronteras que lógicamente beneficiaba a los Estados de Europa oriental. Este ajuste de intereses incide de modo particular en el proceso de continuidad de la Conferencia en el sentido que expondremos más adelante.

11.-El principio VII del Acta de Helsinki es de redacción densa y compleja, cosa que se explica porque, como todo el Acta, fue redactado por consenso, y éste implica difíciles concesiones y transacciones. Pese a todo, el principio reposa sobre la concepción occidental de los derechos del hombre, no sobre la socialista, pues en él se establece expresamente que tales derechos "derivan de la dignidad inherente a la persona humana y son esenciales para su libre y pleno desarrollo". Y en virtud de tal principio, los Estados participantes en la Conferencia se comprometen a respetar los derechos humanos, civiles, políticos, económicos, sociales y culturales y otros derechos y libertades, haciéndose mención específica de algunos de ellos como la libertad de pensamiento, conciencia, religión y creencia, así como los derechos de las minorías nacionales.

Los puntos de referencia para la definición y precisión de estos derechos son la Carta de las Naciones Unidas, la Declaración Universal de los derechos del hombre adoptada por la Asamblea General de las Naciones Unidas el día 10 de diciembre de 1948 y también los acuerdos pertinentes por los que esté obligado cada Estado, incluyendo los Pactos internacionales de las Naciones Unidas de 19 de diciembre de 1966. Hay que decir en cuanto a estas referencias que en el inicio de las negociaciones los países occidentales no habían considerado necesaria la indicación de ningún texto en particular, habida cuenta del carácter particularmente ex. plícito de las disposiciones que proponían respecto a las libertades fundamentales clásicas. Pero los países del Este insistieron 
en la necesidad de mencionar los Pactos de las Naciones Unidas, seguramente porque uno de ellos se refiere a los derechos económicos, sociales y culturales (que a su entender son los realmente importantes) y puesto que, además, los mecanismos de control que establecen tales Pactos son muy tenues y de naturaleza intergubernamental. Las delegaciones occidentales pidieron entonces que se hiciese asimismo referencia a la Declaración Universal de 1948, llegándose a un compromiso favorable para ellas, toda vez que en el principio VII tal Declaración figura al mismo nivel que la Carta de las Naciones Unidas y en tanto que Derecho común en la materia.

Resulta en todo caso que el standard de definición de los derechos humanos que establece el principio VII del Acta de Helsinki es muy alto.

\section{Acuerdos internacionales sobre derechos humanos}

III.-Acabamos de ver que una de las referencias que hace el principio VII para la definición y precisión de los derechos del hombre consiste en los acuerdos y declaraciones por los que pueda estar obligado cada Estado participante. Conviene, pues, precisar cuáles sean los más importantes de estos acuerdos, cuyo ámbito de vigencia nos va a ofrecer de otro lado unos índices claros para apreciar el nivel de respeto de los derechos humanos en los distintos grupos.

En Europa occidental hay que empezar haciendo mención de la Convención europea para la protección de los derechos humanos y las libertades fundamentales, auspiciada por el Consejo de Europa, y firmada en Roma el día 4 de noviembre de 1950, acompañada de cuatro protocolos adicionales. Convención que tiene carácter selectivo en cuanto a los derechos protegidos, pues los que se amparan en ella son fundamentalmente los derechos civiles y políticos, aunque se protegen también el derecho a la instrucción y el derecho a fundar sindicatos. Pero lo realmente interesante y novedoso de la Convención son los mecanismos de protección que establece a cargo de la Comisión, del Tribunal y del Comité de Ministros del Consejo de Europa. No es éste el lugar para hacer una exposición y una valoración detallada del sistema, pero sí vamos a recordar que en el caso de que los Estados hayan aceptado la competencia de la Comisión al respecto, ésta puede recibir reclamaciones de los particulares por la violación de sus derechos, actuando como órgano de encuesta y conciliación. $Y$ los Estados partes pueden también aceptar la competencia del Tribunal, en cuyo caso conoce éste de los asuntos que le sometan la Comisión o los Estados partes, dictando sentencia obligatoria. En la actualidad son 21 los Estados de Europa occidental que han ratificado la Convención; de ellos, 14 han reconocido la competen- 


\section{A. PASTOP RIDEUEJO}

cla de la Comision para recibir reclamaciones de particulares llas excepciones son Chipre, Francia, España, Grecia, Liechtenstein, Malta y Turqua); on cuanto a la Jurisdiccion del Tribunal ha sido aceptada por 17 Estados (siendo las excepciones Chipre, Liechtenstein. Mata y Turquia). Estamos sin duda, pues, ante el instrumento internacional que más lejos ha llegado en una protección inemacional eficaz de los derechos del hombre, lo que se explica por la homogeneidad poltica e ideológica de los Estados que integran al Consejo de Europa.

Dentro asimismo del bloque occionental y en el ámbito de los derechos económicos, sociales y culturales, el Consejo de Europa ha auspiciado otra importante Convención, la Carta Social Europea, finmada en Turín el día 18 de octubre de 1961, de la que son parte hoy 12 Estados (Austria, Chipre, Dinamarca, Republica Federal Ale mana, Francia, Españ, Irlanda, Islandia, Lalia. Nonuega, Suecia y Reino Unido). Claro que ni en el aspecto sustantivo ni en el procesal y orgánico la Carta ha llegado a niveles comparables con los de la Convención de Roma. Sustanivamente, los Estados no tienen que comprometerse a la aceptación global de sus disposicio nes. Procesal y organicamente, el mecanismo de protección no com noce sl sistema de redameciones indviduales no el de órganos con furisdicción obligatoria, menos idóneo politica y técnicamente pare la garanta de los derechos económicos, sociales y culura les. La Carta Social Europea establece únicamente una protección intergubernamental o por vía de informes.

Del círculo de Europa occidental hay que pasar al mucho más amplio de las Naciones Unidas, ámbito lógicamente común a la Europa del Este y la del Oeste. Y en la obra de las Naciones Uni das encontramos en primer término el Pacto internacional sobre derechos económicos, sociales y culturales, de 19 de diciembre de 1966, y en vigor desde el 3 de enero de 1976, instrumento en el que el control del respeto de los derechos enunclados es real mente debil: informes de los Estados sobre medidas adoptadas y progresos realizados que, transmitidos al Secretario General, son examinados por el Consejo Económico y Social. El respero real de los derechos se encomienda, pues, en lo esencial a los ordenamentos internos. De entre los Estados fimantes del Acta Final de Helsinki, acuel Pacto ha sido ratificado de parte occidental por la República Federal Alemana, Cánada, Chipre, Dinamarca, España, Fintandia, Noruega, Reino Unido y Suecia; y de parte de la Eurooa del Este por Bulgaria, Hungría, Polonia, República Democrática Alemana, Bielorrusia, Ucrania, Rumanía, Checosiovaquia, Unión Soviética y Vugostovia.

Hay que registrar también dentro de la obra de las Naciones Unidas, el Pacto internacional sobre derechos civiles y politicos, de la misma fecha que el anterior, y que entró en vigor el dia 23 de marzo de 1976. En el seno de la Conferencia sobre seguridad 
y cooperación en Europa, este Pacto ha sido ratificado, de parte occidental, por la República Federal Alemana, Cánada, Chipre, Dinamarca, España, Finlandia, Noruega, Peino Unido y Suecia; y del lado de la Europa del Este por Bulgaria, Hungría, Polonia, Repúm blica Democrática Alemana, Bielorrusia, Ucrania, Rumanía. Checoslovaquia, Unión Soviética y Vugoslavia. En cuanto a los medios de control de este segundo Pacto hay que decir que son algo más avanzados que en el Pacto anterior, pues por lo pronto todo Es. tado parte puede reconocer opcionalmente la competencia del Comité de Derechos humanos de las Naciones Unidas para recibir y examinar comunicaciones en que otro Estado parte alegue la violación de disposiciones convencionales. Pero los poderes del Con mité no son amplios y tienen lugar según una técnica intergubernamental: además de prestar buenos oficios, puede solicitar expilcaclones y presentar informes. Cabe tamblén que los Estados partes acepten el protocolo facultativo que reconoce la competencia del Comité para recibir y considerar comunicaciones individuales, sobre las que no puede hacer otra cosa que presentar observaciones e inclunlas en el informe anual de sus actividades. Y ni si. quera estos medios opcionales de control han sido aceptados por todos los Estados partes, sino únicamente por algunos, y en el ámbito de la Conferencia sobre Seguridad y Cooperación en Europa sólo por Estados del bloque occidental. La República Federal Alemana, Cánada, Dinamarca, Finlancia, Noruega, Reino Unido y Suecia han admitido la competencia del Comité para recibir comunicaciones de otros Estados. Cénada, Dinamarca, Finlancia, Noruega, Reino Unido y Suecia han reconocido la competencia del Comité para recibir reclamaciones individuales.

Mas en la protección internacional de los derechos del hombre lo que realmente cuenta no es la definición de los derechos y li. bertades, sino la eficacia de los recursos que se pongan a disposición de los particulares ante instancias internacionales de control y garantia. Y desde esta óptica, teniendo en cuenta los datos sucintamente expuestos, la situación únicamente es satisfactoria en Europa occidental, particularmente en el circulo de Estados partes en la Convención de Roma que han aceptado la competencia de la Comisión para recibir reclamaciones individuales y la jurisdicción del Tribunal. Fuera, pues, de dicho círculo, el respeto a los derechos del hombre sigue encomendado en lo esencial a los ordenamientos internos de los Estados.

\section{El control y garantía de los derechos}

IV.-Volviendo a la Conferencia sobre seguridad y cooperación en Europa, hay que decir que en el Acta Final de Helsinki no existe el menor atisbo de un mecanismo institucional de control y garan tía de los derechos humanos ni siquiera intergubernamental o por via de informes, lo que de ningún modo era esperable, dada la 
naturaleza del Acta que no es un tratado internacional, y teniendo en cuenta de otro lado las insuperables dificultades politicas que semejante instauración hubiera encontrado. Porque el ámbito de la Conferencia sobre seguridad y cooperación en Europa no es el del Consejo de Europa. No hay en el la homogeneidad politica e ideológica que impera en la Europa occidental.

Pero de ahí a negar todo valor y operatividad al principio VII del Acta de helsinki y a su cesto tercero va mucha diferencia. Pues en la actualidad, en un plano más politico que juridico, los Estados signatarios del Acta encuentran base para ejercer un drotic de ré. gares sobre el respeto de los derechos humanos por otros Estados participantes.

En el ejercicio de este drofic de regard la iniciativa ha sido de los Estados del occidente, pues no en vano la obligación del respeto de los derechos humanos se incluyó en las negociaciones y en el Acta Final a instancias de ellos, y precisamente como contrapeso al principio de inviolabilidad de las fronteras, segun hemos dicho antes. Es así como en el proceso de continuación de la Conferencia, en el que debe de procederse a un intercambio a fondo de opiniones sobre la aplicación de las disposiciones del Acta Final y ca la ecución de las tareas definidas por la Conterencia", el tema de los derechos humanos ha sido traido a debate por los Esrados occidentales.

En la Conferencia de Belgrado, efectivamente, mientras el jefe de la delegacion de los Estados Unidos resaltó la importancia del tema de los derechos humanos, el jefe de la delegación soviética wuso el énfasis sobre el desarme. Y de otro lado, si las delegaciomes occidentales defendieron el principio de la libertad de exprem sión, asociación y reunión, con la vista puesta en el trato y en los procesos a los disidentes en la Europa del Este, en las escasas faciliades para los trabajos de los periodistas y en la poca ditu. sion del Acta Final, los delegados del Este, ademas de oponer otro de los principios del Acta cual es la no ingerencia en los asuntos internos, pasaron a la ofensiva y acusaron a los Estados occiden. vales de no respetar adecuadamente los derechos económicos, 30 clales y culurales, con el aumento del paro, desigualdades y dis. crininación, e incluso trajeron a colación temas como el hado

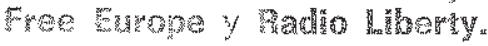

Es muy verosímil que en la próxima Conferencla de Madrid so repitan estas pautas de comportamiento. Sin ánimo de hacer un catblogo exhaustivo de acusaciones es muy probable, en efecto, que las delegaciones occidentales reprochen a la Unión Sociética y a los Estados de Europa oriental de violación de derechos civiles y polícos tales como la detención y procesamiento en la Union Sowética de personas que intentaban ejercer los derechos enunciados en el Acta de Helsinki y vigilar su cumplimiento, o la fata 
de respeto a la libertad de religión y creencia, o la detención de miembros de la Asociación interprofesional libre de trabajadores; en Checoslovaquia la detención y enjuiciamiento de los firmantes de la Carta de los 77 o la represión de actividades religiosas; en la República Democrática Alemana la revisión del Código Penal que, además de ensanchar la definición de los delitos políticos, aumenta las penas, o las restricciones legales a los contactos entre disidentes y periodistas occidentales; en Rumanía la detención y condena de varios disidentes. $Y$ resulta verosímil asimismo que la Unión Soviética y los Estados de Europa oriental repliquen que en los Estados occidentales no se amparan de manera efectiva los derechos económicos, sociales y culturales, especialmente por la falta de seguridad en el trabaio, aumento de las desigualdades, discrinación racial, y que incluso el boycott de la Olimpiada de Moscú está en contradicción con la referencia a los deportes que se hace en el cesto tercero del Acta de Helsinki cuando se habla de los contactos entre personas.

Así las cosas, el clima de la Conferencia de Madrid puede ser, pues, de confrontación y no de cooperación. Ello es una consecuencia inevitable del droi de régard resultante del Acta de Helsinki, pero ho una consecuencia globalmente negativa porque, en todo caso, semejante derecho, que en definitiva es recíproco, puede motivar en los Estados que se sientan observados una mayor sensibilidad hacia el respeto de los derechos humanos. De nuevo sin ánimo exhaustivo, cabe citar en este sentido algunas medidas favorables adoptadas en los países del Este, como la amnistía decretada en la República Democrática Alemana con motivo del trigésimo aniversario de su fundación, que se tradujo en la libertad y salida del país de dos importantes disidentes; o la actitud más tolerante en general hacia los derechos humanos y al trato de los disidentes observada últimamente en Polonia, en donde hay que destacar también la cooperación del Gobierno en la visita del Papa Juan Pablo II. Y en el ámbito del tercer cesto, es indudable que en la Unión Soviética ha aumentado la concesión de permisos a emigrantes sobre todo de raza judia, además de los permisos para visitas temporales. También en Bulgaria, Checoslovaquia, República Democrática Alemana y Hungría ha mejorado la situación en cuanto a la reunificación y los contactos familiares.

$Y$ es que la continuidad de la Conferencia sobre seguridad y cooperación en Europa favorece la aspiración occidental de respeto a los derechos humanos. Si como hemos dicho, tal aspiración fue llevada al Acta de Helsinki como contrapeso de la consaaración de la inviolabilidad de las fronteras deseada por los Estados socialistas, hay que tener en cuenta que tal inviolabilidad está ya conseguida y que su puesta en práctica no necesita de medidas posteriores. En cambio el principio del respeto a los derechos del hombre requiere un proceso dinámico y gradual en el que debe 


\section{A. PATOP PIDRUESO}

de progreser dia a dia y sobre el que cobran especial sentido los intercambios de opiniones acerca de la aplicacion de las disposiciones del Acta Final. Es por ello explicable que el principio VIl del Decátogo y el tercer cesto relativo a la cooperación human. tarla sean puntos especianente sensibles en la continuidad de la Conterencia.

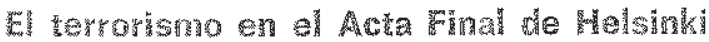

y.-Un fenomeno cuyas relaciones con el tema de los derechos del hombre son profundas y complejas es el del terrorismo. pues ocurre, por lo pronto, que el terrorismo, institucionalizado o de grupos individuos, constituye una flagrante y gravisima violacion de los derechos humanos. En este sentido, los Estados están obli gados a combatilo pero no sólo en sus resultados, sino tambien y fundamentamente en sus causas. En lo que atañe a los resultados det terrorismo, es cierto que se pueden manifestar de ma nera más alamante en un regimen respetuoso de las liberades civiles y politicas que en un sistema autortario, y ello explica hesta qué punto las democracia parlamentarias occidentales son vichmas del terrorismo de grupos e individus. Pero tal consideración no debe servir de tentación ni pretexto para recortar las Ibertades. Nás aun, si de un lado el respeto de los derechos del hombre excluye de por sí el terrorismo del Estado, de otro lado, la promoción global y protunda de tales derechos, incluyendo el de autodeterminación de los pueblos, es el modo idóneo de hacer desaparecer no tanto los resultados como las causas del terro rismo de grupos e individuos.

Hay que decir por ello que, dentro del Acta de Helsinki, el tra wamiento más profundo del fenómeno terrorista es el que hace el principio VII del Decálogo así como el cesto tercero sobre coope. racion humanitaria. Claro que ya son sabidas las limitaciones de uno y otro al conflar el respeco efectivo de los derechos del hombre y aquella cooperación a los ordenamientos internos de los Estados.

Sin embargo, en otro principio del Decálogo hay una mención expresa del terrorismo. Se trata del principlo Vl sobre no intervención en los asuntos internos, en cuyo útimo párrafo se dice gue los Estados participantes "se abstendrán, entre otras cosas, de prestar asistenola drecta o indirecta a las actividades terroristas o a las actividades subversivas o de otro tipo encaminadas a derrocar por la volencla el régimen de otro Estado participan. te". El Acta Final de Helsinki contempla eo nomine el terrorismo en el contexto del principio de no intervención en los asuntos in ternos. Y la obligación que asumen los Estados participantes es elemental y genérica, al igual que la tormulada en el mismo con- 
Lexto por la Declaración 2625 (XXV) de la Asamblea General de las Naciones Unidas sobre principios de Derecho intemacional que rigen las relaciones de amistad y cooperacion entre los Estados, y no se ve acompanada de mayores precisiones, desarrollos garantias.

En el ámbito de la Conferencia de Seguridad y Cooperación en Europa era dificil haber llegado más lejos si se piensa que la con cepción del terrorismo intemacional no es la misma en los tsat dos occidentales y en los de la Europa del Este. Ello ya se puso de relieve en las discusiones habidas en la XXVIl sesión de la Asamblea General de las Naciones Unidas (1972). Alli, el secretario general, introdujo el problema bajo el epigrafe de amedidas para prevenir el terrorismo y otras formas de violencla que ponen en peligro vidas humanas inocentes o causan su pérdida o com. prometen las libertades fundamentales", pero la Asamblea General decidió añadir al enunciado "el estudio de las causas subyacentes de las formas de terrorismo y de los actos de violencla que tienen su origen en las aflicciones, la frustración, los agravios y la desesperanza, y que conducen a algunas personas a sacrificar vïdas humanas, incluida la propla, en un intento de lograr cambios radicales" Es decir, de una consideración jurídica de los resultados del terrorismo se pasó a otra política que ponía el énfasis en sus principales causas. $Y$ sil la primera perspectiva era esencialmente occidental, la segunda respondía a una concepción tercermundista apoyada por los Estados socialistas del Este de Europa.

Pero es que incluso en el círculo más homogeneo de los Estados de Europa occidental, y en el contexto de una concepción jurídica del terrorismo preocupada sólo por sus resultados, la cooperación interestatal no ha alcanzado resultados satisfactorios. Es cierto que en el seno del Consejo de Europa se firmó el día 27 de enero de 1977 la convención europea sobre represión del terrorismo", pero no es menos verdad que, además de permitir muy importantes reservas, no estamos ante otra cosa que ante un convenio multilateral de extradición por actos terroristas que en buena parte no se tiplfican debidamente como delitos.

\section{Conclusión}

VI.-Estas sucintas noticias y estas breves reflexiones sobre los derechos humanos en el Viejo Continente y en el ámbito de la Conferencia sobre seguridad y cooperación en Europa demuestran la importancia capital que ha alcanzado el tema en las relaciones Este-Oeste. $Y$ con resultados no desdeñables en absoluto desde una perspectiva realista. Porque, por lo pronto, el hecho de que en materia de derechos del hombre se haga bandera del Acta de Helsinki es sumamente significativo. Ademés la dialéctica ha 


\section{J. A. PASTOR RIDRUEJO}

contribuido a una mayor sensibilización por el problema en los mass media y en la opinión pública y ha producido la consecuencia de que los Estados se consideren legitimados para observar y se sientan asimismo legítimamente observados, lo que les constrine a practicar mayores niveles de respeto de los derechos humanos. Aunque sólo fuese por ello habría que desear vivamente la celebración de la Conferencia de Madrid y que en ella no se detenga la continuidad del proceso iniciado en Helsinki. 